\title{
Effect of Reinforcing Particle Shape on the Behavior of Composites Materials
}

\author{
K. Mansouri*, B. Chermime, A. Saoudi, H. Djebaili, A. Litim, Z. Kabouche
}

University Abbes Laghrour, 40000 Khenchela, Algeria

(Received 01 November 2021; revised manuscript received 02 December 2021; published online 20 December 2021)

\begin{abstract}
In this paper, the effect of particle shape on the mechanic behavior of glass particle reinforced composites is evaluated. Small particles adhere strongly to the polymer, which leads to a strong reinforcing effect. When the total contact surface increases, more loads are transferred to the reinforcing particles. In our previous studies, it has been shown that addition of circular particles with decreasing diameter does not affect the composite. The objective of this research is to investigate the mechanical behavior of thermoplastic matrix composite nylon 66, reinforced with glass particles, under unidirectional tensile loading using finite element analysis. Numerical results are presented for a variety of particle shapes, including circular, triangular, square, rhombic, pentagonal and hexagonal. The results show that Von Mises stresses consistently increased as the shape of the reinforcing particles changed from triangular to square, rhombic, pentagonal, hexagonal and circular in this order.
\end{abstract}

Keywords: Particles, Nylon 66, Composite, Shape effect, Tensile loading, Finite element.

\section{INTRODUCTION}

The addition of rigid reinforcing materials to polymer materials is an established practice in the polymer industry. By introducing a rigid second phase, substantial improvements in stiffness, strength, creep performance, and fracture toughness can be obtained. Reinforcing materials are usually spherical, plate-like or fiber-like. Fiber is often used as a reinforcing material, although this usually leads to anisotropy. This may cause problems and change the size of the components. Therefore, when tight tolerances or isotropic properties are required, spherical or plate-like particle fillers are sometimes a better choice [1]. In fact, thermoplastics can be repeatedly softened by increasing temperature and hardened by cooling. This is the opposite of thermosetting plastics. Once cured, they cannot be altered or reshaped at elevated temperatures [2]. Compared to metal parts, thermoplastics have many advantages, including weight, ease of manufacture, and cost effectiveness. Although these advantages enable them to proliferate in various industries, the lack of structural load-bearing capacity hinders their use in the automotive and aerospace industries [3]. The overall material cannot meet certain material requirements in advanced industries. Therefore, composite materials have been developed. The combination of the required properties of thermoplastics and glass particles (high strength and high modulus) is the goal of composite production [4]. The high cost and technical difficulties encountered in the production of fiber-reinforced composite materials sometimes limit their use in many applications [5]. Particle-reinforced materials are more attractive because they are cost-effective, isotropic, and can be processed using similar techniques for monolithic materials [6]. The effective behavior of macroscopically isotropic particle-reinforced two-phase composites is primarily determined by the fabric behavior and volume fractions of the matrix and inhomogeneities. The details of the geometric arrangement of the constituents and, therefore, the shapes of the particles play solely secondary roles [7]; a decrease in the particle diameter (circular) does not have an effect on the composite [8]. The particles are used to increase the modulus of the matrix, reduce permeability, and reduce ductility. Young's modulus is the stiffness (ratio between stress and strain) of a material in the elastic phase of a tensile test. Since the rigidity value of solid particles is much higher than that of the matrix, it can be significantly improved by adding micro- and nanoparticles to the polymer matrix [9].

A particle can have one dimension or not have a long dimension. Composite materials consist of particles of one material dispersed in a matrix of another material. Generally, the particles are spherical, elliptical, polyhedral, or irregular in shape. The particles are added to the liquid matrix and then solidified in some process. The particles can be treated or untreated during the enhancement process. They are used to increase the strength or other properties of cheap materials during reinforcement with other base materials [10]. Kamalbabu concluded that reinforced composites with smaller particle sizes show better tensile properties than other composites. Morphological analysis shows that smaller particles are evenly distributed in the matrix, and the fracture surface is smooth [11]. The objective of this research is to investigate the mechanical behavior of thermoplastic matrix composite nylon 66, reinforced with glass particles, under unidirectional tensile loading by finite element analysis, in which different shapes are used (circular, triangular, square, rhombic, pentagonal and hexagonal).

\section{THEORETICAL ANALYSIS}

The improvement in mechanical properties has led to great interest in nanocomposites. The mechanical properties of particle-reinforced materials depend on the bond between the particles and the matrix and the quality of the particles. Since particles and a matrix

*mansouri.khelifa@univ-khenchela.dz 
often have quite different elastic moduli, the stress in each must be different; in fact, the stress is higher in a material with a higher elastic modulus (usually particles) [12]. The bonding of particle-matrix can be improved by increasing the contact surface area between the matrix and reinforcement [13], and the same can be said about nanocomposites, when the particle diameter decreases, the contact surface area increases. The ultimate strength strongly depends on the stress transfer between the particles and the matrix [14]. Factors like type, size distribution, agglomeration state/dispersion, chemical deposition, crystal structure, surface area, surface chemistry, surface charge, shape/morphology, dissolution/solubility, physical/chemical properties of nanoparticles affect the properties of composite materials [15].

The development of micromechanical equations for the particulate composites follows along the same lines as those for the short fiber reinforced composites. In the case of particulate reinforced composites, the particles in various shapes and sizes are dispersed uniformly in the binder material. This is similar to the case of short fiber reinforced composites, in which the fibers are assumed to be arranged in a regular array pattern such as a square or hexagon. The distance between particles decreases when the volume fraction increases. At a higher volume fraction of particles, the distance becomes very small [12].

The mechanical performance of particle-reinforced thermoplastics is affected by the following factors: composition and morphology, type and amount of reinforcement, interface (or interphase) between the matrix and reinforcement, processing methods and conditions, test conditions [16].

The following assumptions have been made or are implicit in modern micromechanics of particulate composites: a composite is composed of two phases - particles and a matrix, each phase of a composite can be described by continuum mechanics. Hence, the input parameters are moduli, Poisson's ratios of individual phases, micromechanics is characterized by average values of composite properties and average constituent stresses over a certain region. It is assumed that the interface between the particle and the matrix is a perfect bond, and the properties of individual phases are isotropic.

Table 1 - Particle length calculation for different shapes $\left(V_{f}=20 \%\right)$

\begin{tabular}{|c|c|c|c|c|}
\hline No & Particles & Shape & Particle length $(\mu \mathrm{m})$ & $l_{p}$ values $(\mu \mathrm{m})$ \\
\hline 1 & Triangle (equilateral) & $\triangle^{\mathbf{L}_{\mathbf{p}}}$ & $l_{p}=\sqrt{2 V_{f} l_{m}^{2} / N_{p} \times \sin 60^{\circ}}$ & $l_{p}=26.49$ \\
\hline 2 & Square & $\left.\square\right|_{p} ^{\mathbf{L}_{\mathbf{p}}}$ & $l_{p}=\sqrt{V_{f} l_{m}^{2} / N_{p}}$ & $l_{p}=17.37$ \\
\hline 3 & Rhombus & $\bigcup_{\mathbf{L}_{\mathbf{p}}}$ & $l_{p}=\sqrt{V_{f} l_{m}^{2} / N_{p}}$ & $l_{p}=17.37$ \\
\hline 4 & Pentagon & $\square_{\mathbf{L}_{\mathbf{p}}}$ & $l_{p}=\sqrt{4 V_{f} l_{m}^{2} \tan 36^{0} / 5 N_{p}}$ & $l_{p}=13.18$ \\
\hline 5 & Hexagon & $\square_{\mathbf{L}_{\mathbf{L}}}$ & $l_{p}=\sqrt{2 V_{f} l_{m}^{2} / 3 \sqrt{3} \times N_{p}}$ & $l_{p}=19.78$ \\
\hline 6 & Circle & $\bigcirc^{\mathbf{d}_{\mathbf{p}}}$ & $d_{p}=\sqrt{4 V_{f} l_{m}^{2} / \pi N_{p}}$ & $d_{p}=19.61$ \\
\hline
\end{tabular}

In Table $1, V_{f}$ is the particle volume fraction, $N_{p}$ is the number of particles, $l_{m}$ is the matrix length, $l_{p}$ is the particle length; $d_{p}$ is the particle diameter.

In what follows, we will study the shape effect of $\left(N_{p}=16\right)$ glass particles on the mechanical behavior of the composite. The matrix is assumed to be square with a length of $l_{m}=155.425 \mu \mathrm{m}$, the particle sizes $l_{p}$ and $d_{p}$ are calculated for different values of $V_{f}$ and are given in Table 1.

\section{MODELING}

The finite element software Castem was used to develop the models and generate the results. Composites with sixteen particles of triangular, square, rhombic, pentagonal, hexagonal and circular shapes were modeled for three types of arrangement (square, hexagonal and random), all six shapes had the same area but different perimeters. To more easily understand the shape effect of reinforcing particles, plane strain element behavior was selected in this study. Particles were assumed to be perfectly bonded to the matrix material. Composites were modeled and meshed with triangular elements to achieve the best convergence and accuracy of the results. The composite was subject- ed to a uniform tensile stress $\sigma$.

\subsection{Composite Property}

Each element has an isotropic property. The model is small, so a fine mesh of elements is used [17]. For simplicity, it is assumed that all particles have the same diameter $d_{p}$ [18] for a circular shape and the same

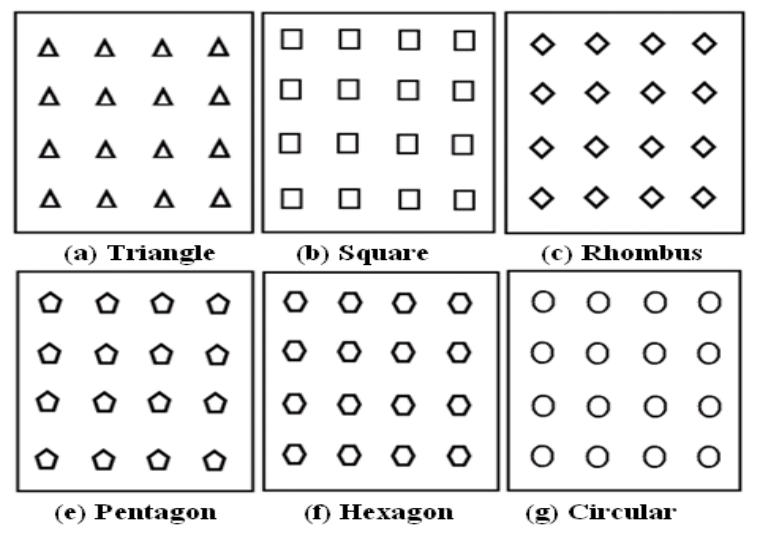

Fig. 1-Different shapes used in the simulation (square arrangement) 
length $l_{p}$ for other shapes. Due to axial symmetry, the specimen can be considered as a $2 \mathrm{D}$ elastic body. In all calculations, the following parameters are used [19]: reinforcing glass particles with Young's modulus $E_{p}=64 \mathrm{GPa}$, Poisson ratio $v_{p}=0.2$, and density $\rho_{p}=2.54 \mathrm{~g} / \mathrm{cc}$; the matrix is made of nylon $66(\mathrm{~Pa})$ with Young's modulus $E_{m}=3 \mathrm{GPa}$, Poisson ratio $v_{m}=0.35$, and density $\rho_{m}=1.14 \mathrm{~g} / \mathrm{cc}$.

\subsection{Boundary Conditions}

Boundary conditions representing the application of tensile loads to the particulate composite, i.e., for $x=0$ and $x=l_{m}, U_{y}=0$, the matrix and particles have zero motion in the $y$-direction (Fig. 2). Here the $x$-axis is in the direction of length, and the model is axis-symmetric with respect to it. We applied $F_{x}=5.65 \times 10^{-8} \mathrm{n} / \mu \mathrm{m}^{2}$ [20] at the end faces of the matrix, i.e., for $x=0$ and $x=l_{m}$.

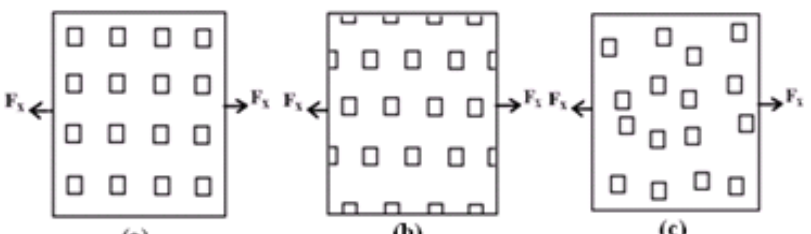

(a)

(b)

(c)

Fig. 2-Boundary conditions for a composite reinforced with 16 square particles: (a) square arrangement, (b) hexagonal arrangement, (c) random arrangement

\section{RESULTS AND DISCUSSION}

Fig. 3a represents the von Mises stress distribution in a composite reinforced with square particles. It can be seen that the stresses were highly concentrated at the ends of the particles. In Fig. 3b, c, f, it can be seen that the von Mises stresses are located at the corners of particles. For a triangular shape (Fig. 3d), the stresses are highest at the base of the triangle, which is parallel to the applied force direction. Finally, for a circular shape, it can be seen that the stress is concentrated in the central particles and in the lateral arc for other particles Fig. 3e.

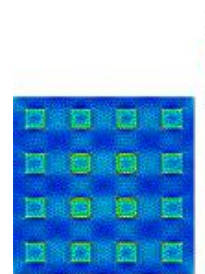

(a)Square

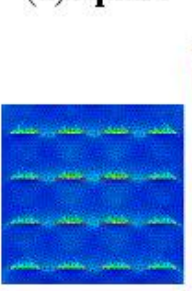

(d) Triangle

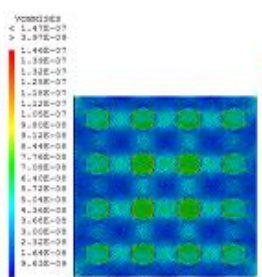

(b) Hexagon

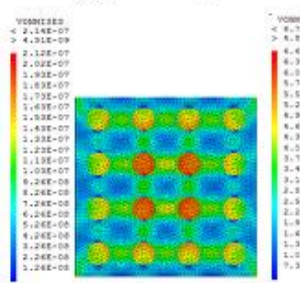

(e) Circular

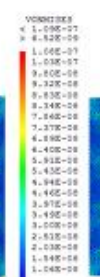

(c) Pentagon
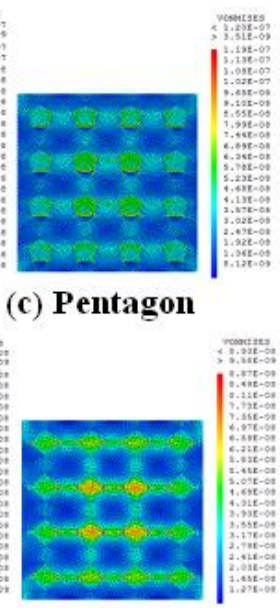

(f) Rhombus
Fig. 3 - Von Mises stress distribution for different shapes of particles with $V_{f}=20 \%$

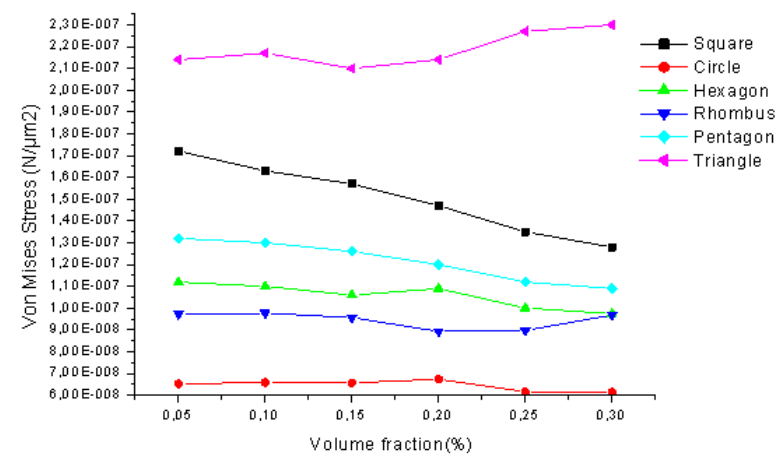

Fig. 4 - Evolution of von Mises stress depending on particle volume fraction for square packing

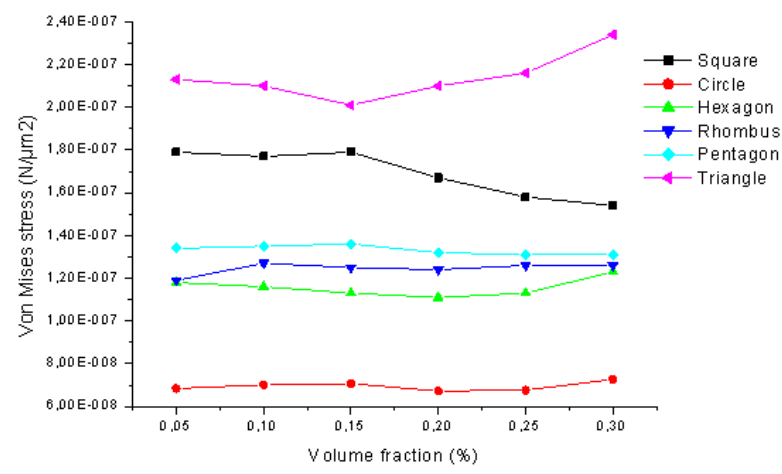

Fig. 5 - Evolution of von Mises stress depending on particle volume fraction for random packing

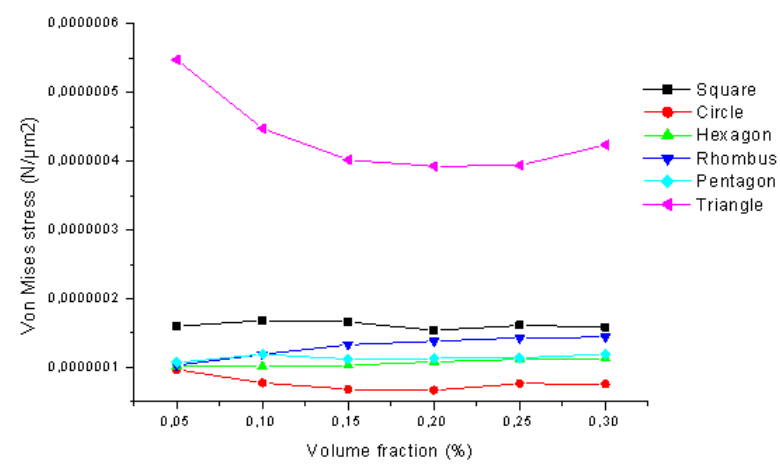

Fig. 6 - Evolution of von Mises stress depending on particle volume fraction for hexagonal packing

Fig. 4 represents the evolution of von Mises stresses depending on the volume fraction of particles for different shapes and for square arrangement. It should be noted that the stress values in the triangular-shaped particles are much higher compared to other particle shapes, followed by square, pentagonal, hexagonal, rhombic and finally circular shapes. It can be assumed that when the particle shape increases with an angle from triangular to hexagonal and finally circular, the resistance of the composite also increases. Note that as the volume fraction of particles increases, the von Mises stresses increase in triangular shape. We also notice that the curve of square particles decreases because this composite behaves like a composite reinforced with short fibers.

Fig. 5 and Fig. 6 represent stresses for other arrangements (random and hexagonal, respectively). The same remark as for the square arrangement, the only 
difference is that in the hexagonal arrangement the stress values in triangular shape are much higher compared to other shapes. It can also be seen that some of the composites have increased von Mises stresses in the region located between the particles (Fig. 3), the reason is that a plastic zone is created in this location, which can lead to fracture in this matrix zone between the reinforcements. We can conclude from the previous results that the circular shape is the ideal shape for better resistance of composites reinforced by particles.

\section{CONCLUSIONS}

In conclusion, as the volume fraction of the reinforcement increased, the particle size decreased, the total surface between the matrix and the reinforcement increased. As the total contact surface increased, more loads were transferred to the reinforcing particles, and, consequently, the overall stiffness of the composites increased. The shape of particles is an important factor in improving the resistance of composite materials. It is also interesting to note that the variation of stiffness increased steadily as the shape of the reinforcement changed from triangular to circular. However, the thermoplastic nylon 66 matrix with circular glass particles showed better resistance than all other shapes. The shape and dispersion of the particles affect the behavior of thermoplastic matrix composite.

\title{
REFERENCES
}

1. A. Sjögren, Failure Behaviour of Polypropylene/Glass Bead. Composites (Luleå University of Technology S-971 87 Luleå: Sweden: 1995).

2. K. Slim, Prom. Micromechanical Modeling of the Progressive Failure in Short Glass-Fiber Reinforced Thermoplastics (Doghri: Issam: Delannay: Laurent: 2011).

3. A. Kulkarni, N. Aswini, C.R. Dandekar, S. Makhe, International Conference on Structural Nano Composites (NANOSTRUC: 2012).

4. N. Parvin, M. Rahimian, Acta Phys. Pol. A 121 No 1, 108 (2012).

5. Subodh K. Mital, Pappu L.N. Murthy, Robert K. Goldberg, NASA (1996).

6. Nikhilesh Chawla, Yu-Lin Shen, Adv. Eng. Mater. 3 No 6 , 357 (2001).

7. Helmut J. Böhm, A. Rasool, Int. J. Solid Struct. 87, 90 (2016).

8. K. Mansouri, H. Djebaili, M. Brioua, J. Nano- Electron. Phys. 12 No 5, 05004 (2020).

9. S.Y. Fu, X.Q. Feng, B. Lauke, Y.W. Mai, Compos. Part B 39, 933 (2009).

10. A. Kanagaraj, C. Franciskennathamreth, M. Ajithkumar, V. Anandh, R. Nagaraj, IJRAIIT 5 No 2, 280 (2019).

11. P. Kamalbabu, G.C. Mohan Kumar, Procedia Mater. Sci. 5, 802 (2014)

12. K. Mansouri, H. Djebaili, M. Brioua, RCMA 27 No 3/4, 261 (2017).

13. E.G. Koricho, D.T. Reda, AIMS Mater. Sci. 6 No 6, 1191 (2019).

14. M. Hossein Alaei et al., IPJ (2013).

15. C.S.C. Santos, B. Gabriel, M. Blanchy, et al., IAN 2, 456 (2015).

16. H. Gould, J. Tobochnik, Computer Simulation Methods. Applications to Physical Systems (New York: AddisonWesley Publishiong: 1988).

17. S. Houshyar, R.A. Shanks, A. Hodzic, Exp. Polym. Lett. 3 No 1, 2 (2009).

18. H.F. Lei, Z.Q. Zhang, B. Liu, Compos. Sci. Technol. 72, 506 (2012).

19. J.F. O’Gara, Glen E. Novak, M.G. Wyzgoski, Delphi Research Labs (2010).

20. Prince, M. Verma, S. Singh, IJERA 287 (2012).

\section{Вплив форми армуючих частинок на поведінку композиційних матеріалів}

\author{
K. Mansouri, B. Chermime, A. Saoudi, H. Djebaili, A. Litim, Z. Kabouche
}

University Abbes Laghrour, Khenchela, 40000, Algeria

\begin{abstract}
У роботі оцінено вплив форми частинок на механічну поведінку композитів, армованих частинками скла. Дрібні частинки міцно прилипають до полімеру, що призводить до сильного армуючого ефекту. При збільшенні загальної контактної поверхні на армуючі частинки передаеться більше навантаження. У наших попередніх дослідженнях було показано, що додавання круглих частинок із діаметром, що зменшуеться, не впливае на композит. Метою даної роботи є дослідження механічної поведінки термопластичних матричних композитів Nylon 66, армованих скляними частинками, при односпрямованому розтягуючому навантаженні за допомогою аналізу кінцевих елементів. Числові результати представлені для різних форм частинок, включаючи круглу, трикутну, квадратну, ромбічну, п'ятикутну та шестикутну. Результати показують, що напруження фон Мізеса послідовно збільшувалося в міру того, як форма армуючих частинок змінювалася з трикутної на квадратну, ромбічну, п'ятикутну, шестикутну та круглу в такому порядку.
\end{abstract}

Ключові слова: Частинки, Nylon 66, Композит, Вплив форми, Розтягуюче навантаження, Кінцевий елемент. 